\title{
Pengaruh Fraksi Volume Dan Panjang Serat Pelepah Lontar (Borassus Flabellifer) Terhadap Kekuatan Tarik Dan Kekuatan Impak Komposit Bermatrik Epoksi
}

\author{
Amros Alfonsius Tuati ${ }^{\star}$, Anindito Purnowidodo, Achmad As'ad Sonief \\ Teknik Mesin Universitas Brawijaya Indonesia, MT Haryono, 167 - Malang \\ (65145) - Indonesia \\ E-mail: amrost@ymail.com
}

\begin{abstract}
This study was conducted using epoxy resin as ligature and midrib lontar fibers (borassus flabellifer) as brace. Composite was made by varied fiber volume fraction $10 \%, 30 \%$ and $50 \%$ with length variation $10 \mathrm{~mm}, 20 \mathrm{~mm}$, and $30 \mathrm{~mm}$. The composite production used hand lay-up method. The test result showed the highest composite tensile strength about $31.607 \mathrm{Mpa}$ in volume fraction $10 \%$ with fiber length $30 \mathrm{~mm}$. The lowest composite tensile strength was about $16.855 \mathrm{Mpa}$ in fiber volume fraction $10 \%$ and $20 \mathrm{~mm}$ in fiber length. Moreover, the highest composite impact strength was $0.00163 \mathrm{~J} / \mathrm{mm}^{2}$ in fiber volume fraction $50 \%$ with fiber length $30 \mathrm{~mm}$ and the lowest impact strength was $0.00214 \mathrm{~J} / \mathrm{mm}^{2}$ in fiber volume fraction $10 \%$ and $10 \mathrm{~mm}$ fiber length. The kind of composite fracture tended to have brittle fracture with mechanism of fiber pull out.
\end{abstract}

Keywords : Midrib Lontar Fibers, Volume Fraction, Fiber Length and Epoxy Composite Impact Strength.

\section{PENDAHULUAN}

Pohon Lontar (Borassus Flabellifer) di Nusa Tenggara Timur merupakan jenis palma yang dikenal sebagai pohon kehidupan bagi masyarakat. Pada tumbuhan ini hampir semua bagian bermanfaat bagi umat manusia, antara lain sebagai bahan pangan, bangunan, perabot rumah tangga dan barang kesenian dan budaya

Jumlah populasi pohon lontar menurut Distanbud NTT (2009) sekitar 10406,409 ha [1]. Sehingga dapat dikatakan bahwa populasi pohon lontar cukup berkembang di propinsi NTT. Akan tetapi hingga saat ini dapat dikatakan bahwa tanaman lontar masih merupakan salah satu jenis flora NTT yang belum dimanfaatkan secara optimal.

Pengelolahan bagian pohon lontar seperti pelepah lontar, selama ini hanya dimanfaatkan sebagai sampah organik maupun sebagai bahan bakar pengganti minyak tanah untuk memasak. Dilihat dari pemanfaatan pohon lontar yang masih terbatas, maka sangat baik apabila serat yang ada pada pelepah lontar dijadikan sebagai penguat untuk material komposit.

Komposit merupakan kombinasi antara dua material atau lebih yang berbeda bentuknya, komposisi kimianya dan tidak saling melarutkan antara materialnya dimana material yang satu berfungsi sebagai penguat dan material lainnya berfungsi sebagai pengikat untuk menjaga kesatuan unsurunsurnya [2].

Kongkeaw, $\mathrm{P}$, et.al melakukan penelitian menggunakan serat bambu sebagai penguat dan matrik epoksi sebagai pengikat. Hasilnya menunjukan bahwa kekuatan tarik meningkat dengan adanya pertambahan panjang serat 2,4,6,8,10 mm. Kekuatan tarik tertinggi ada pada komposit dengan panjang serat $10 \mathrm{~mm}$ [3]. Raghavendra, et.al meneliti tentang pengaruh variasi panjang serat pisang $(2,4,6 \mathrm{~mm})$ terhadap kekuatan mekanik komposit. Hasil penelitian menunjukan kekuatan tarik tertinggi ada pada panjang serat $4 \mathrm{~mm}$ sebesar 158 Mpa dan kekuatan impak tertinggi $20,3 \mathrm{~J} / \mathrm{m}$ pada panjang serat $6 \mathrm{~mm}$ [4].

Penelitian ini menggunakan serat pelepah lontar dengan memvariasikan fraksi volume serat dan variasi panjang serat. Harapannya dapat mengetahui seberapa besar pengaruh fraksi volume serat dan variasi panjang serat pelepah lontar 
(Borassus Flabellifer) terhadap kekuatan mekaniknya.

\section{METODOLOGI PENELITIAN}

Metode penelitian yang digunakan adalah eksperimen nyata (true experimental research) yang bertujuan untuk mengetahui pengaruh variasi fraksi volume dan panjang serat pelepah lontar (SPL) terhadap kekuatan tarik dan impak komposit bermatrik epoksi.

Pada penelitian variasi volume serat yang digunakan adalah $10 \% \mathrm{SPL}, 30 \% \mathrm{SPL}$, $50 \%$ SPL dengan variasi panjang SPL yaitu $10 \mathrm{~mm}, 20 \mathrm{~mm}$ dan $30 \mathrm{~mm}$.

Serat sebelum digunakan diberi perlakuan alkali $5 \% \mathrm{NaOH}$ per 1 liter aquades dengan uppset time 180 menit. Tujuan adalah untuk membersihkan kotoran pada permukaan serat serta memperbaiki struktur permukaan serat sehingga mampu meningkatkan ikatan interface antara serat dan resin.

\section{Bahan dan Peralatan Penelitian}

a. Bahan

1. Matrik

Dalam penelitian ini digunakan matrik epoksi tipe 108 sebagai pengikat

2. Serat (fiber)

Sebagai penguat (natural fiber) adalah serat pelepah lontar (Borassus Flabellifer)

3. Katalis

Katalis yang digunakan adalah katalis Methyl Ethyl Keton Peroxide (MEKPO) sebesar $1 \%$ volume resin dengan bentuk cair berwarna bening.

4. $\mathrm{NaOH}$ dan Aquadest

Digunakan untuk proses alkalisasi serat pelepah lontar $5 \%$ per 1 liter aquades

b. Peralatan Penelitian

1. Alat Cetak

Dibuat dari mika dengan ukuran standard ASTM D6110 untuk spesimen uji impak dan ASTM D638-00 untuk spesimen uji tarik.

2. Timbangan Digital

Tipe : $100 \mathrm{G} / 0,01 \mathrm{G}$

3. Mesin Uji Tarik Serat Tunggal Spesifikasi : Type IMADA Capasity 50-60 $\mathrm{N}$

4. Mesin Uji Tarik
Spesifikasi : Type Gotech Testing

Machine, Capasity $5000 \mathrm{~kg}-10000 \mathrm{~kg}$

5. Mesin Uji Impak

Spesifikasi : Charpy Pendulum Impact Testing Machine, impact Velocity 2,9 m/s, Rising angle $150^{\circ}$.

\section{Pembuatan Spesimen}

Pembuatan specimen dicetak sesuai dengan standar Uji Tarik ASTM D639-00 [5] dan standar Uji Impak ASTM D6110 [6]. Pencetakan menggunakan metode hand lay up.

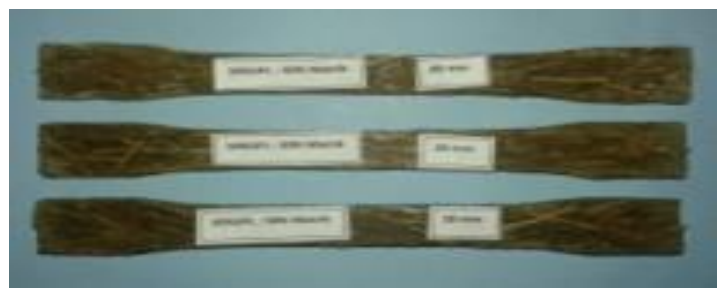

Gambar 1. Material Uji Tarik ASTM D639-00

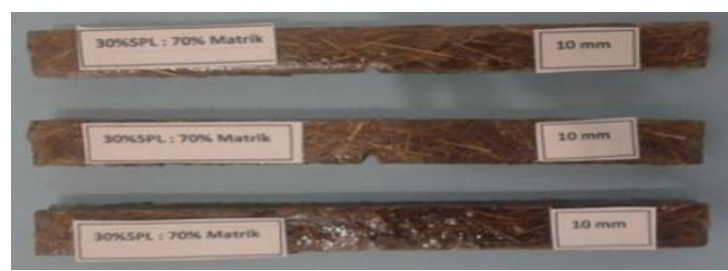

Gambar 2. Material Uji Impak ASTM D6110

\section{HASIL DAN PEMBAHASAN \\ Kekuatan Tarik Serat Dan Matrik}

Berdasarkan data hasil pengujian kekuatan tarik serat pelepah lontar dan kekuatan tarik matrik pada tabel 1. maka kita dapat mengetahui kekuatan tarik komposit secara teoritis seperti pada Gambar 3.

Tabel 1. Data Kekuatan Tarik Serat Pelepah Lontar Dan Matrik (Epoksi)

\begin{tabular}{|l|l|l|}
\hline Sifat & $\begin{array}{l}\text { Serat } \\
\text { Pelepah } \\
\text { Lontar }\end{array}$ & $\begin{array}{l}\text { Matrik } \\
\text { (Epoksi) }\end{array}$ \\
\hline $\begin{array}{l}\text { Kekuatan } \\
\text { Tarik (Mpa) }\end{array}$ & 548,14 & 21,869 \\
\hline
\end{tabular}

Dari Gambar 3, diketahui kekuatan tarik komposit teoritis meningkat seiring dengan 
adanya pertambahan volume serat. Kekuatan tarik tertinggi yaitu 285,005 Mpa. Secara teoritis dapat dianalisa penyebab meningkatnya kekuatan tarik komposit adalah karena adanya pertambahan serat sebagai penguat di dalam komposit. Sedangkan kekuatan tarik sebenarnya (actual) nilai kekuatan tarik kompositnya lebih rendah dibandingkan kekuatan tarik teoritis. Penyebab rendahnya nilai kekuatan tarik sebenarnya (actual) dipengaruhi oleh banyak faktor misalnya, fiber pull out, void, campuran katalis serta orientasi serat yang tidak merata pada seluruh bagian komposi. Lebih jelasnya dapat dilihat pada gambar 4 kekuatan tarik komposit (actual)

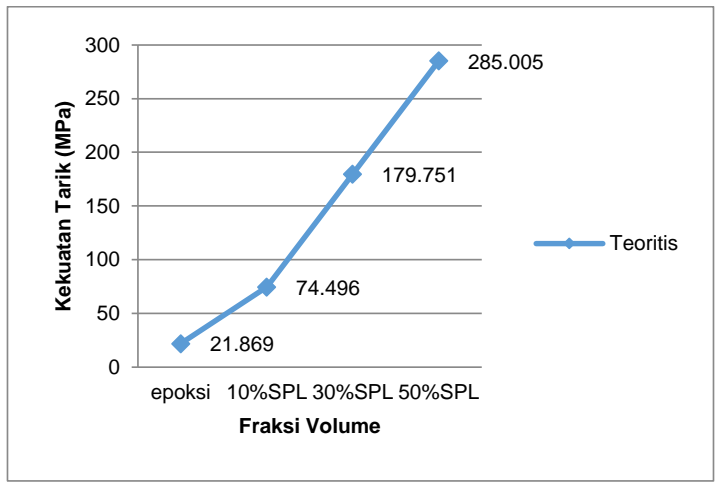

Gambar 3. Hubungan Kekuatan Tarik Komposit Vs Fraksi Volume Serat Pelepah Lontar (Teoritis)

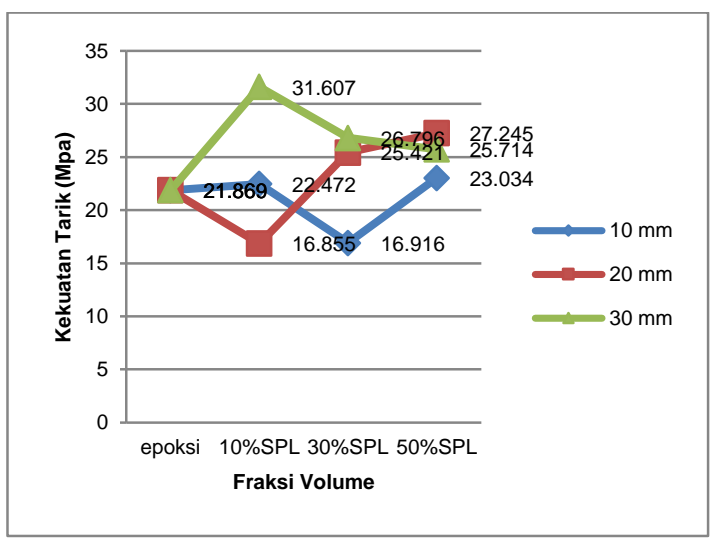

Gambar 4. Hubungan Rata-Rata Kekuatan Tarik Komposit Vs Fraksi Volume Serat Pelepah Lontar (SPL).
Berdasarkan hasil pengujian kekuatan tarik pada gambar 4. Kekuatan tarik rata-rata komposit tertinggi untuk panjang serat 10 $\mathrm{mm}, 20 \mathrm{~mm}, 30 \mathrm{~mm}$ yaitu 23,034 Mpa untuk fraksi volume 50\% SPL, 27,245 Mpa untuk fraksi volume $50 \%$ SPL dan 31,607 Mpa untuk fraksi volume 10\% SPL. Sedangkan rata-rata kekuatan tarik komposit terendah untuk panjang serat $10 \mathrm{~mm}, 20 \mathrm{~mm}, 30 \mathrm{~mm}$ yaitu $16,916 \mathrm{Mpa}$ untuk fraksi volume serat $30 \%$ SPL, 16,855 Mpa untuk fraksi volume $10 \%$ SPL dan 25,714 Mpa untuk fraksi volume $50 \%$ SPL.

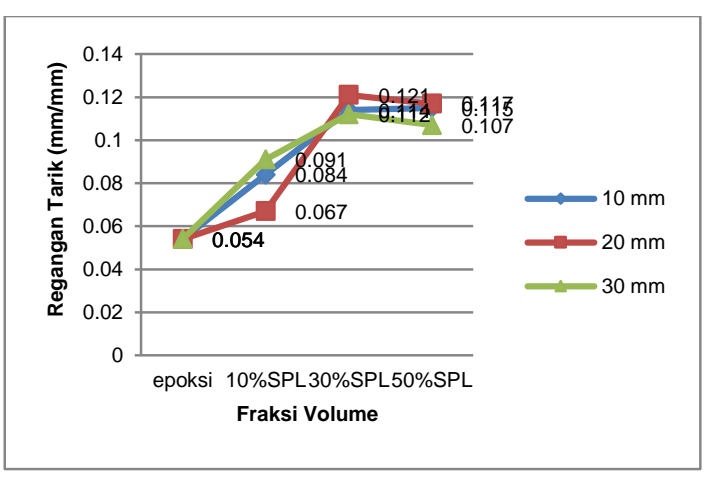

Gambar 5. Hubungan Rata-Rata Regangan Tarik Komposit Vs Fraksi Volume Serat Pelepah Lontar (SPL).

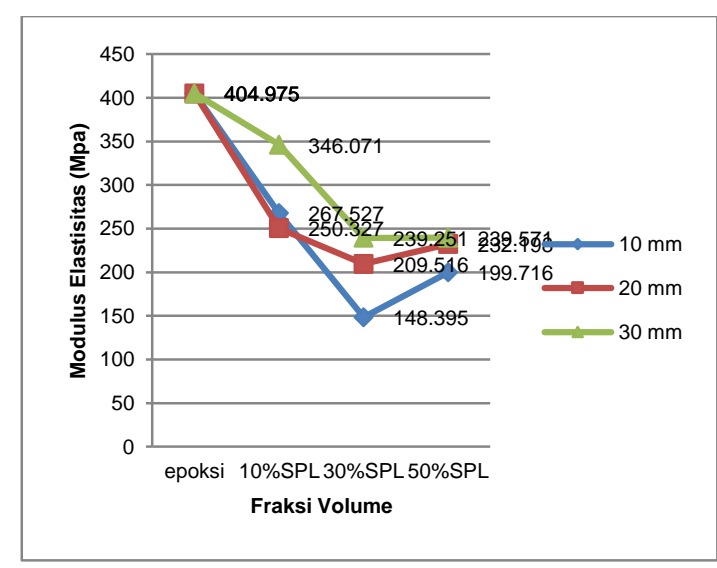

Gambar 6. Hubungan Rata-Rata Modulus Elastisitas Komposit Vs Fraksi Volume Serat Pelepah Lontar (SPL).

Dari gambar 5, diketahui bahwa regangan tarik komposit tertinggi untuk panjang serat $10 \mathrm{~mm}, 20 \mathrm{~mm}, 30 \mathrm{~mm}$ yaitu 0,115 untuk fraksi volume $50 \%$ SPL, 0,121 
untuk fraksi volume $30 \%$ SPL dan 0,112 untuk fraksi volume $30 \%$ SPL. Sedangkan regangan tarik komposit terendah untuk panjang serat $10 \mathrm{~mm}, 20 \mathrm{~mm}, 30 \mathrm{~mm}$ yaitu 0,084 untuk fraksi volume serat $10 \%$ SPL, 0,067 untuk fraksi volume $10 \%$ SPL dan 0,091 untuk fraksi volume $10 \%$ SPL.

Dari gambar 6, diketahui bahwa nilai modulus elastisitas komposit tertinggi untuk panjang serat $10 \mathrm{~mm}, 20 \mathrm{~mm}, 30 \mathrm{~mm}$ yaitu 267,527 Mpa untuk fraksi volume 10\% SPL, 250,327 Mpa untuk fraksi volume 10\% SPL dan 346,071 Mpa untuk fraksi volume 10\% SPL. Sedangkan modulus elastisitas komposit terendah untuk panjang serat 10 mm, 20 mm, 30 mm yaitu 148,395 Mpa untuk fraksi volume serat 30\% SPL, 209,516 Mpa untuk fraksi volume $30 \%$ SPL dan 239,251 Mpa untuk fraksi volume $30 \%$ SPL.

\section{Kekuatan Impak Komposit}

Berdasarkan pengujian dan pengolahan data hasil kekuatan impak, maka dibuatlah grafik Energi Serap (gambar 7) dan Kekuatan impak komposit (gambar 8) seperti pada gambar dibawah ini.

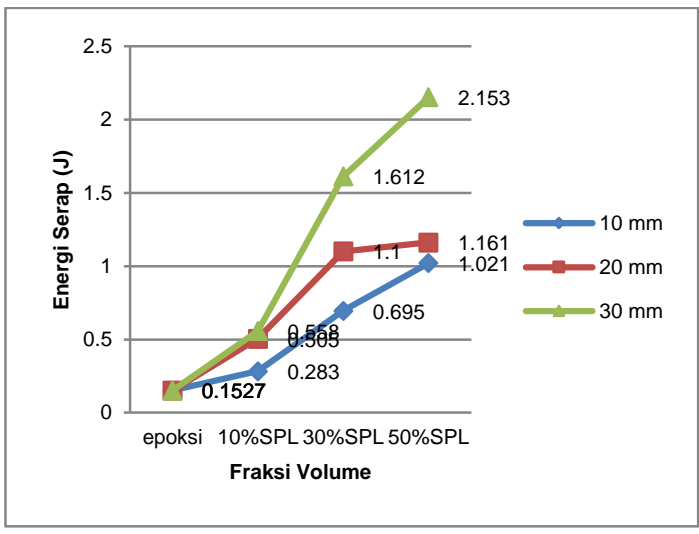

Gambar 7. Hubungan Rata-rata Energi Serap Vs Fraksi Volume Serat Pelepah Lontar

Dari gambar 7 dan 8, diketahui energi serap dan kekuatan impak komposit meningkat seiring dengan bertambahnya fraksi volume serat dan panjang serat. Energi serap maksimun ada pada komposit dengan fraksi volume $50 \%$ SPL dengan panjang serat $30 \mathrm{~mm}$ sebesar 2,153 J, sedangkan energi serap terendah adalah 0,1527 J pada epoksi (matrik). Sedangkan pada gambar grafik 10, kekuatan impak tertinggi ada pada fraksi volume $50 \%$ SPL dengan panjang serat 30

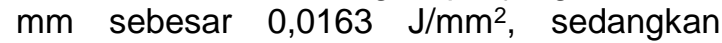
kekuatan impak terendah adalah 0,00116 $\mathrm{J} / \mathrm{mm}^{2}$ pada epoksi (matrik).

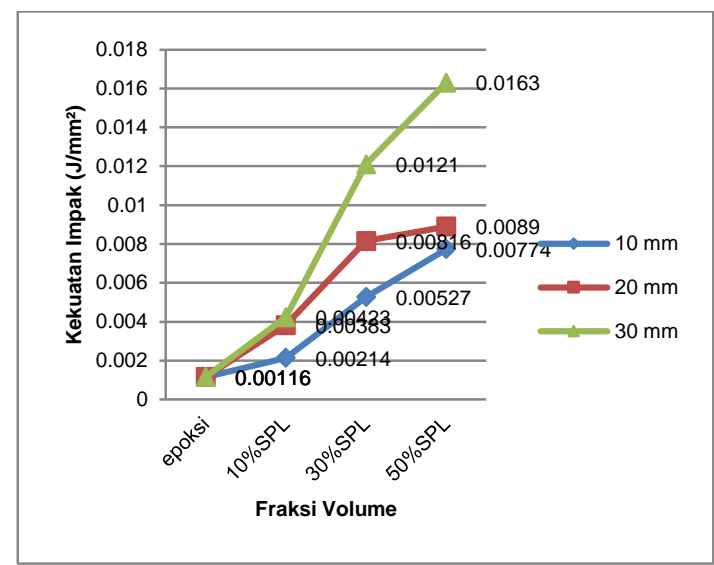

Gambar 8. Hubungan Rata-rata Kekuatan Impak Komposit Vs Fraksi Volume Serat Pelepah Lontar

\section{Analisa Foto Makro Patahan Komposit}

a. Material Komposit Uji Tarik
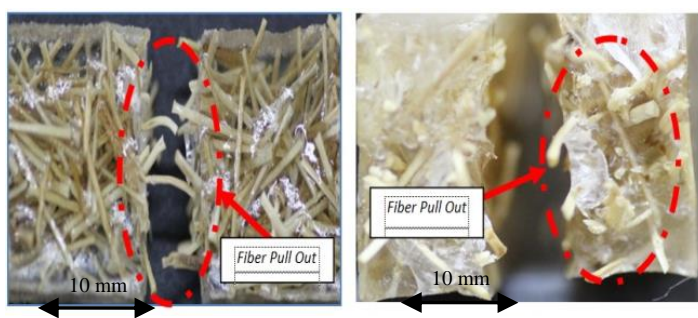

Gambar 9. Komposit (panjang serat $10 \mathrm{~mm}$ )

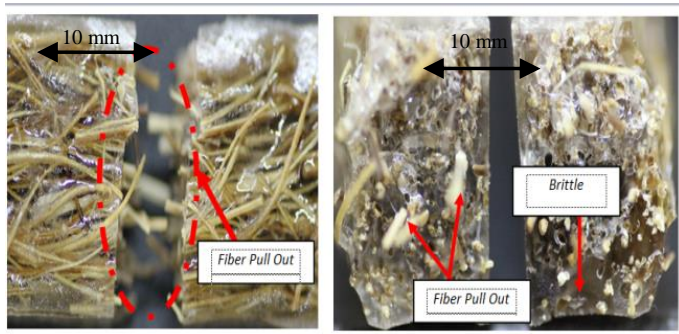

Gambar 10. Komposit (panjang serat $20 \mathrm{~mm}$ ) 

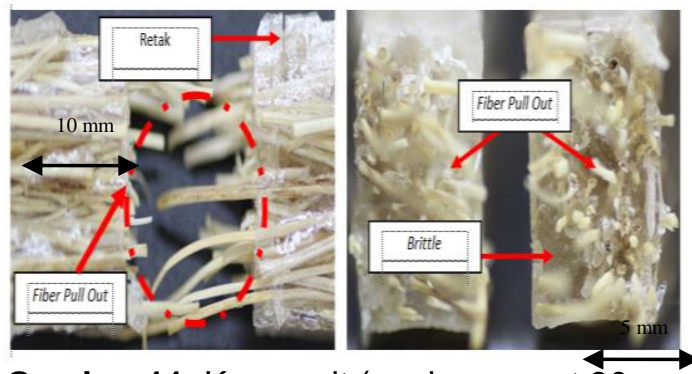

Gambar 11. Komposit (panjang serat $\overrightarrow{30 \mathrm{~mm}}$

b. Material Komposit Uji Impak
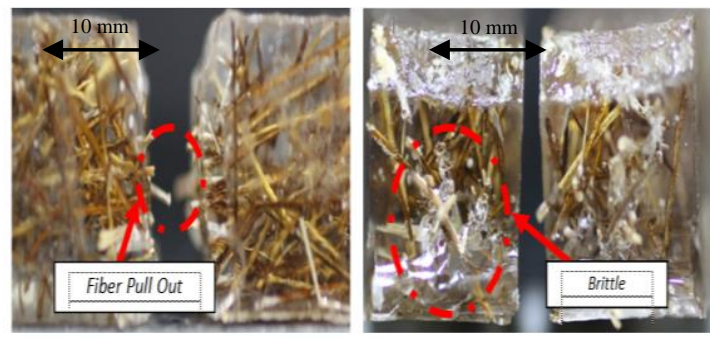

Gambar 12. Komposit (panjang serat $10 \mathrm{~mm}$ )
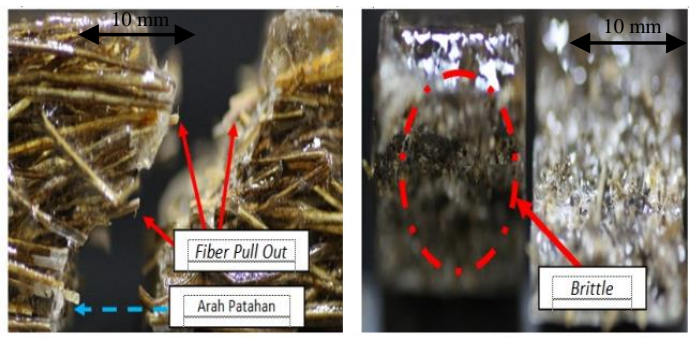

Gambar 13. Komposit (panjang serat $20 \mathrm{~mm}$ )
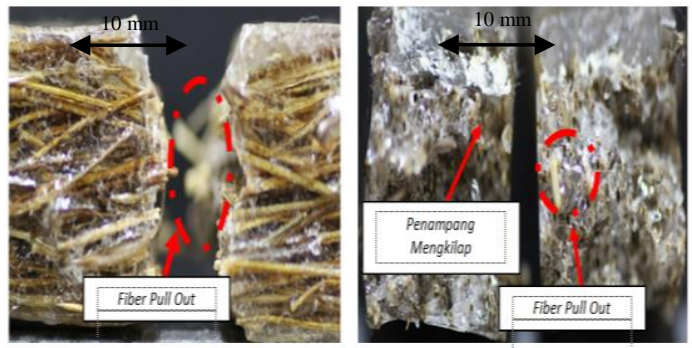

Gambar 14. Komposit (panjang serat $30 \mathrm{~mm}$ )

Berdasarkan hasil foto makro pada material komposit uji tarik dan impak, maka diketahui pola patahan komposit cenderung mengalami patah getas (brittle), hal tersebut terlihat pada permukaan penampang patahan yang kelihatan mengkilap seperti bercahaya. Hal ini menandakan patahan yang terjadi adalah patah getas atau brittle dengan cenderung mengalami mekanisme fiber pull out.

\section{KESIMPULAN}

1. Rata-rata kekuatan tarik tertinggi ada pada komposit dengan fraksi volume $10 \%$ SPL dengan panjang serat $30 \mathrm{~mm}$ yaitu 31,607 Mpa. Sedangkan kekuatan tarik terendah ada pada komposit dengan fraksi volume 10\% SPL dengan panjang serat $20 \mathrm{~mm}$ yaitu 16,855 Mpa.

2. Rata-rata kekuatan impak tertinggi ada pada komposit dengan fraksi volume $50 \%$ SPL dengan panjang serat $30 \mathrm{~mm}$ yaitu $0.0163 \mathrm{~J} / \mathrm{mm}^{2}$. Sedangkan kekuatan impak terendah ada pada komposit dengan fraksi volume 10\% SPL dengan panjang serat $10 \mathrm{~mm}$ yaitu $0.00214 \mathrm{~J} / \mathrm{mm}^{2}$.

3. Pola patahan komposit impak maupun tarik dengan variasi volume 10\% SPL, $30 \%$ SPL, $50 \%$ SPL dengan variasi panjang serat $10 \mathrm{~mm}, 20 \mathrm{~mm}$ dan 30 $\mathrm{mm}$, cenderung mengalami patah getas (brittle) dan mekanisme fiber pull out.

\section{DAFTAR PUSTAKA}

[1] Badan Penelitian dan Pengembangan Kehutanan Kementrian Kehutanan, 2010. Lontar (Borassus Flabellifer) Sebagai Sumber Energi Bioetanol Potensial.

[2] Gibson, R.F.1994. Principle of Composite Material Mechanics. Departement of Mechanical Engineering Wayne State University Detroit, Michigan.

[3] Kongkeaw.P, Nuapeng.W, Thamajaree.W, The Effect of Fiber Length on Tensile Properties of Epoxy Resin Composites Reinforced By The Fibers of Bamboo (Thyrsostachys Siamensis Gamble). Journal of the Microscopy Society of Thailand 4 (1), 46-48 2011.

[4] S. Raghavendra, P. Balachandrashetty, P.G Makunda, K.G Sathyanarayana (2012), The Effect Of Fiber Length on Tensile Properties Of Epoxy Resin Composite Reinforced By Fiber Of Banana. (IJERT). ISSN: 2278-0181 Vol.1. 
[5] ASTM, D6110, Standard Test Method for Determining the Izod Pendulum Impact Resistance of Plastics. Philadelphia, PA: American Society for Testing and Materials.
[6] ASTM, D638-00, Standard Test Method for Tensile Properties of Plastic. Philadelphia, PA: American Society For Testing and Materials. 